\title{
UDALJENO PRIKUPLJANJE PODATAKA O POTROŠNJI VAZDUHA POD PRITISKOM AUTOMATIZOVANIH SISTEMA
}

\section{REMOTE DATA COLLECTION ABOUT COMPRESSED AIR CONSUMPTION OF AUTOMATED SYSTEMS}

\author{
Đorđe Ungar, Fakultet tehničkih nauka, Novi Sad
}

\begin{abstract}
Oblast - INDUSTRIJSKO INŽENJERSTVO
Kratak sadržaj - Osnovni zadatak ovog rada jeste projektovanje aplikacije za udaljeno prikupljanje podataka o potrošnji vazduha pod pritiskom automatizovanih sistema koja nosi ime ShareBOX. Svrha aplikacije je da skladišti rezultate merenja dobijenih pomoću Festo Air Box portabilne laboratorije $i$ da se ti rezultati merenja podele sa ostalim kolegama ili saradnicima radi zajedničke analize.
\end{abstract}

Ključne reči: Vazduh pod pritiskom, pneumatika, udaljeno prikupljanje podataka, veb aplikacija, API

\begin{abstract}
The main goal of this thesis is to design an application for remote data collection about compressed air consumption of automated systems, titled ShareBOX. The purpose of this application is to collect the results of measurements obtained by the Festo Air Box portable laboratory and share it with peers for a common analysis.
\end{abstract}

Keywords: Compressed air, pneumatics, remote data collection, web application, API

\section{UVOD}

Vazduh pod pritiskom i prevođenje njegove potencijalne energije $u$ mehaničku je jedan od najrasprostranjenijih oblika energije korišćenih $u$ industriji. Prednosti pneumatskih uređaja kao što su mala masa, jednostavno održavanje, fina regulacija brzine $\mathrm{i} / \mathrm{ili}$ sile pritiska, jednostavnost konstrukcije, robusnost, neosetljivost na preopterećenje, i mala opasnost od nesrećnih slučajeva, čine ih veoma popularnim alatima $u$ industriji. Pneumatski alati se koriste za obavljanje raznih zadataka $\mathrm{u}$ industrijskim pogonima kao što su rukovanje materijalom, čišćenje, alatne mašine, farbanje, peskarenje, pakovanje itd.

Industrijska postrojenja koja koriste pneumatske alate i mašine, troše vazduh pod pritiskom kao osnovni energetski resurs, međutim, često se ne uviđa da je vazduh pod pritiskom jedan od najskupljih vrsta energije. Samim tim, postoji veliki potencijal za optimizaciju troškova odnosno povećanje energetske efikasnosti pneumatskih sistema u industriji [1].

\footnotetext{
NAPOMENA:

Ovaj rad proistekao je iz master rada čiji mentor je bio prof. dr Dragan Šešlija.
}

Vršenje postupaka održavanja kao i unapređivanje energetske efikasnosti postojećih pneumatskih sistema podrazumeva prikupljanje podataka o potrošnji vazduha pod pritiskom, i njihovu analizu, čime je moguće izvršiti i analizu efikasnosti posmatranog pneumatskog sistema, kao i otkrivanje eventualnih kvarova u pneumatskom sistemu.

Glavni fokus ovog rada jeste projektovanje i izrada aplikacije za udaljeno prikupljanje podataka o potrošnji vazduha pod pritiskom automatizovanih sistema izmerenih pomoću Festo Air Box portabilne laboratorije tip GHDA-FQ-M-FDMJ-A. Ovaj proces obuhvata analizu postojećeg postupka vršenja merenja potrošnje vazduha pod pritiskom pomoću Air Box uređaja, zatim analizu zahteva zainteresovanih strana, utvrđivanje kriterijuma za razvoj aplikacije, odnosno funkcionalnih i nefunkcionalnih zahteva, zatim odabir tehnologija za razvoj aplikacije, i konačno razvoj i implementaciju programskog rešenja.

\section{VAZDUH POD PRITISKOM}

Vazduh pod pritiskom je bezbedan i pouzdan izvor energije i koristi se u više od $90 \%$ industrijskih postrojenja. Za razliku od električne energije, gasa ili vode, koji se takođe koriste u fabrikama, jedino se vazduh pod pritiskom generiše na samom mestu upotrebe. Celokupan ciklus od proizvodnje vazduha pod pritiskom, preko distribucije i upotrebe, odvija se unutar samog industrijskog postrojenja. Upravo iz razloga što se proces može sagledati u celosti, postoji veliki broj mogućnosti za povećanje efikasnosti sistema vazduha pod pritiskom, bilo smanjenjem troškova proizvodnje, bilo regulisanjem pritiska, protoka, kvaliteta vazduha pod pritiskom, itd.

\subsection{Kvalitet vazduha pod pritiskom}

Nečistoće u vazduhu pod pritiskom mogu da izazovu kvarove na pneumatskoj opremi i alatima, takođe, $\mathrm{u}$ nekim proizvodnim sistemima gde vazduh pod pritiskom dolazi u direktan kontakt sa finalnim proizvodom (kao na primer $\mathrm{u}$ prehrambenoj industriji, farmaceutici ili elektronici), nedovoljan kvalitet vazduha pod pritiskom može da dovede do smanjenog kvaliteta samog proizvoda, stoga je izuzetno bitno da vazduh pod pritiskom zadovoljava određeni predefinisani nivo kvaliteta.

ISO, svetska organizacija za standarde, ustanovila je standard kojim se definišu klase kvaliteta vazduha pod pritiskom. Prema ovom standardu moguće je deklarisati 
kvalitet vazduha pod pritiskom koristeći tri jednocifrena broja, koji odgovaraju klasama pomenutog standarda za maksimalni dopušteni sadržaj nečistoća u vazduhu pod pritiskom. Poslednja revizija standarda je iz 2010. godine [2].

\subsection{Upravljanje potrošnjom vazduha pod pritiskom}

Nekada efikasni sistemi za distribuciju vazduha pod pritiskom mogu postati neefikasni usled rasta sistema preko granica za koje je sistem projektovan [1]. Usled dotrajalosti opreme za proizvodnju i pripremu vazduha pod pritiskom može doći do curenja vazduha pod pritiskom, što se preventivnim održavanjem može sprečiti.

Efektivno upravljanje pneumatskim sistemom i donošenje bilo kakve upravljačke odluke ili aktivnosti održavanja je praktično nezamislivo bez nekakve kvantifikacije svih gore navedenih karakterističnih atributa vazduha pod pritiskom koje je jedino moguće dobiti pomoću uređaja za merenje vazduha pod pritiskom.

\subsection{Uređaji za merenje potrošnje i kvaliteta vazduha pod pritiskom}

Za merenje potrošnje i kvaliteta vazduha pod pritiskom, kao i za otkrivanje eventualnih kvarova u sistemima vazduha pod pritiskom koristi se širok spektar uređaja, od detektora gasa, preko ultrazvučnih detektora i termalnih kamera, do portabilnih laboratorija i senzorskih stanica.

Uređaj Air Box tip GHDA-FQ-M-FDMJ-A kompanije Festo je portabilna laboratorija koja omogućava merenje pritiska, temperature i protoka vazduha, kao i utvrđivanje kvaliteta, odnosno količine ulja i vlage u vazduhu pod pritiskom u pneumatskim sistemima. Air Box poseduje mnoštvo vazdušnih kanala kojima se vazduh sprovodi unutar uređaja i koji omogućavaju širok spektar merenja, kao što su: kvalitet, pritisak, protok i temperatura vazduha pod pritiskom [3].

\section{DEFINISANJE KRITERIJUMA ZA RAZVOJ APLIKACIJE}

\subsection{Analiza postojećeg sistema}

Postupak merenja potrošnje vazduha pod pritiskom pomoću Air Box uređaja vrši se tako što tehničar na terenu poveže Air Box uređaj na odgovarajuće grane unutar posmatranog pneumatskog sistema, i izvrši jedno ili više merenja pomoću Air Box uređaja, obično i u pasivnom i u aktivnom režimu rada sistema. Nakon toga se podaci sa uređaja prebacuju na računar koristeći specijalizovani softver za komunikaciju sa Air Box uređajem, što je grafički prikazano na slici 1 .

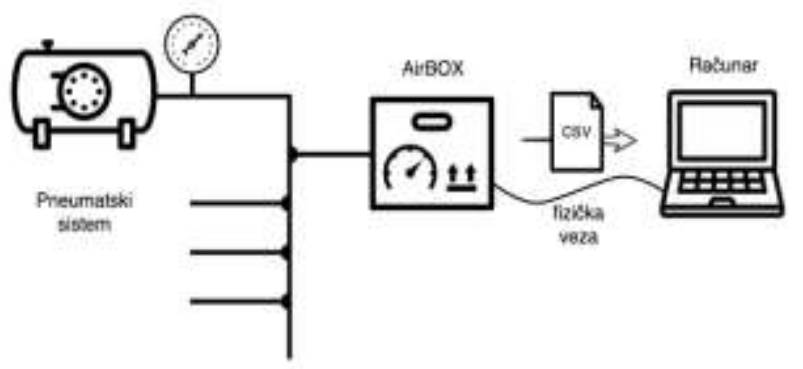

Slika 1: Šematski prikaz postupka merenja pomoću Air Box uređaja
Izmereni podaci se putem elektronske pošte šalju stručnom licu na dalju analizu. Nakon prijema izmerenih podataka, stručno lice vrši analizu podataka pomoću specijalizovanog Air Box softvera, koji prikazuje podatke u vidu interaktivnog grafikona.

Jedan od glavnih nedostataka u ovom procesu predstavlja nepostojanje centralnog arhiva merenja, pa je svaki član tima primoran da vodi sopstveni arhiv merenja, što često dovodi do nekonzistentnosti arhiva između članova tima, kao i do problema kada je potrebno da se pronađe neko konkretno merenje.

\section{RAZVOJ APLIKACIJE}

Nakon analize zahteva odlučeno je da se aplikacija za udaljeno prikupljanje o potrošnji vazduha pod pritiskom automatizovanih sistema projektuje kao veb aplikacija. Struktura veb aplikacije se prirodno nadovezuje na postojeći proces merenja potrošnje vazduha pod pritiskom, opisanom u poglavlju 3.1 a datom na slici 1 . Umesto da se izmereni podaci šalju putem e-mail poruke, tehničar koji je izvršio merenje izmerene podatke šalje putem interneta na veb server koji opslužuje veb aplikaciju, nakon čega izmerene vrednosti postaju dostupne drugim kolegama, omogućavajući im da, iako nisu na terenu, izvrše analizu izmerenih vrednosti preko svojih veb pregledača. Šematski prikaz ovog procesa dat je na slici 2.

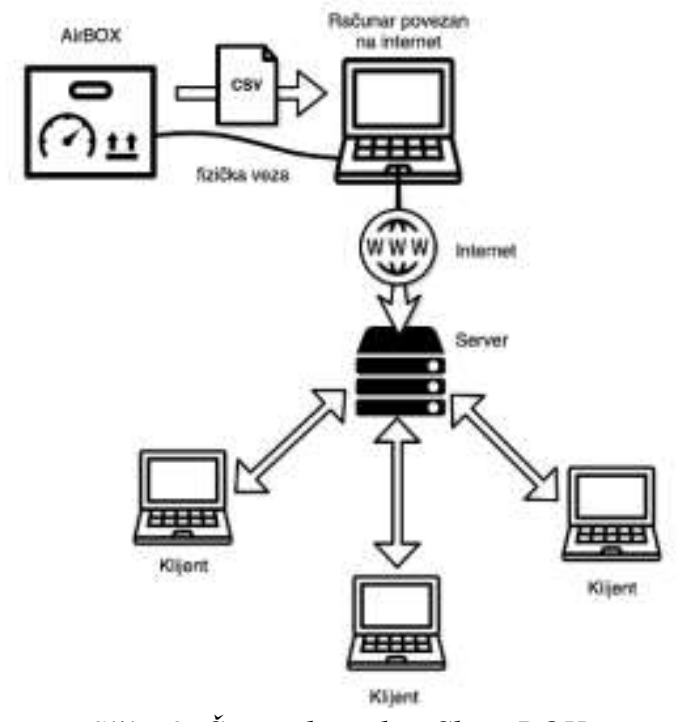

Slika 2: Šematski prikaz ShareBOX sistema

\subsection{Odabir tehnologija}

Aplikacija za udaljeno prikupljanje podataka o potrošnji vazduha pod pritiskom je osmišljena kao veb aplikacija, gde je serverski deo zadužen za aplikativnu logiku, dok je klijentski deo zadužen za prezentaciju korisničkog interfejsa u vidu HTML stranice. Uslovljeno zahtevom da se za razvoj i funkcionisanje aplikacije koristi softver slobodnog kôda, odlučeno je da aplikacija koristi LAMP stek tehnologija, koji podrazumeva Linux operativni sistem, Apache veb server, MySQL sistem za upravljanje relacionim bazama podataka i PHP programski jezik.

Kao osnovu za ovaj projekat korišćena je Codeigniter platforma, koja je u vreme razvoja ove aplikacije bila jedna od najpopularnijih PHP veb platformi otvorenog 
kôda, zasnovana na MVC (eng. "Model-View-Controller") paradigmi za razvoj dinamičkih veb stanica $u$ PHP-u [4].

Codeigniter platforma obezbeđuje zaštitu od raznih vrsta napada na sistem od strane zlonamernih korisnika, kao što su SQL Injection (ubrizgavanje SQL kôda), XSS (Cross Site Scripting), XSRF (Cross Site Request Forgery), itd. što je od izuzetnog značaja za bezbednost veb aplikacije.

Dodatni izazov prilikom razvoja aplikacije predstavljalo je projektovanje interaktivnog grafikona za prikaz izmerenih vrednosti. Svaka od popularnih JavaScript biblioteka za iscrtavanje grafikona (D3, C3, Chart.js, Flot, itd.) se pokazala kao prespora za iscrtavanje grafikona od podataka dobijenih iz Air Box uređaja, čak i za merenja koja imaju samo nekoliko hiljada tačaka. Iz ovog razloga odlučeno je da se napiše nova biblioteka za iscrtavanje grafikona u JavaScript-u, koja je optimizovana za sučajeve korišćene u ShareBOX aplikaciji i bez problema prikazuje merenja koja imaju i preko 65 hiljada tačaka.

\section{API - APLIKACIONI PROGRAMSKI INTERFEJS}

API, odnosno aplikacioni programski interfejs, je alat koji se koristi za deljenje sadržaja i podataka između softverskih aplikacija [5]. API određuje rečnik i konvencije pozivanja koje programer treba da primeni kako bi koristio usluge koje servis pruža.

ShareBOX veb servis implementira API koji omogućava drugim aplikacijama i uređajima da komuniciraju sa ShareBOX aplikacijom. U praktičnom smislu ovo znači da je moguće konstruisati uređaj ili aplikaciju koja može da šalje podatke ShareBOX aplikaciji. Na primer, Arduino mikrokontroler sa senzorom pritiska koji šalje podatke ShareBOX aplikaciji u određenim vremenskim intervalima. Ovo je izuzetno moćan koncept, jer predstavlja osnovu za projektovanje kompleksnijih softverskih rešenja za kontinualno nadgledanje pneumatskih sistema.

\section{PRIMER KORIŠĆENJA APLIKACIJE}

\subsection{Instalacija i konfigurisanje okruženja}

Za pravilno funkcionisanje ove aplikacije, neophodno je instalirati odgovarajuće softverske pakete koji omogućavaju nesmetan rad ShareBOX aplikacije. Kao što je već napomenuto, ova aplikacija je napisana u PHP-u, koristi MySQL sistem za upravljanje relacionim bazama podataka i sve to služi Apache HTTP server. Ova tri programska paketa se često instaliraju zajedno u paketu poznatijem kao WAMP (što je akronim od Windows, Apache, MySQL, PHP) kada je u pitanju Windows operativni sistem, ili LAMP (Linux, Apache, MySQL, PHP) kada je u pitanju Linux.

Pojedinačna instalacija i podešavanje ovih paketa može biti prilično kompleksna i vremenski zahtevna za prosečnog korisnika. Da bi se omogućila jednostavnija instalacija svih neophodnih softverskih paketa koristi se koncept poznat kao virtualizacija. Virtualizacija, u kompjuterskoj nauci, predstavlja kreiranje virtuelnog sloja između računarskog hardvera i softvera koji je na njemu instaliran. Virtualizacija omogućava simulaciju jednog hardverskog sistema unutar drugog, osiguravajući nezavisnost između dva sistema.

Jedan od najpoznatijih softverskih paketa za virtualizaciju jeste VirtualBox [6] kompanije Oracle, dok je za upravljanje virtualnim okruženjima najpopularnija softverska alatka Vagrant [7], kompanije HashiCorp.

VirtualBox omogućava kreiranje virtualnog okruženja, dok Vagrant omogućava automatizaciju tog procesa.

Koristeći Vagrant softverski paket, kreiran je instalacioni skript koji omogućava automatizovanu instalaciju ShareBOX aplikacije i svih neophodnih softverskih paketa za njeno pravilno funkcionisanje.

Nakon izvršenja instalacione skripte, veb aplikacija će biti dostupna na adresi: "https://sharebox.local" ("https://172.16.33.33" za operativni sistem koji nema mogućnost DNS multikasta), putem bilo kog modernog veb pregledača.

\subsection{Prikaz udaljenog merenja potrošnje vazduha pod pritiskom}

Kao što je već pomenuto, Air Box uređaj se koristi kao prenosni instrument za merenje potrošnje i kvaliteta vazduha pod pritiskom na određenoj lokaciji. Potrebno je povezati uređaj na posmatranu granu pneumatskog sistema i uključiti ga.

Pomeranjem kontrolnog dugmeta, postoji mogućnost selekcije procedure merenja od interesa. Odabirom statičkog merenja, vrši se provera nivoa curenja vazduha u sistemu, dok se dinamičkim merenjem vrši provera potrošnje vazduha tokom rada sistema.

Nakon izvršenog merenja, podaci koji se čuvaju u radnoj memoriji data logera, se prebacuju na računar koristeći specijalizovan softver MSR-Reader.

Datoteka se zatim uvozi u ShareBOX aplikaciju tako što se kreira novo merenje (http://sharebox.local/merenja/novo), gde se nakon unosa naziva i opisa merenja, odnosno korisničke grupe kojoj će merenje biti vidljivo, odabere datoteka sa izmerenim vrednostima, i klikom na dugme „Kreiraj merenje“, podaci pošalju na server, gde se podaci iz datoteke uvoze u centralni registar merenja aplikacije ShareBOX.

Nakon kreiranja merenja, izmereni podaci postaju dostupni svim korisnicima koji pripadaju korisničkoj grupi u kojoj je kreirano merenje, omogućavajući im dalji pregled i detaljnu analizu.

\section{DISKUSIJA}

Napisanom aplikacijom omogućen je brz pregled i analiza merenja potrošnje vazduha pod pritiskom dobijenih pomoću Air Box uređaja. Ujedno, postignuta je relativna lakoća i jednostavnost u korišćenju. Mogućnost da se pristup određenom merenju dozvoli samo određenoj grupi korisnika predstavlja jednostavan način da se obezbedi privatnost podataka u multi-korisničkom okruženju.

Pošto je ShareBOX aplikacija u osnovi veb aplikacija, dostupnost aplikacije zavisi isključivo od dostupnosti servera, odnosno od dostupnosti internet konekcije. 
Pošto je klijentski deo aplikacije napisan koristeći HTML tehnologije, nema potrebe za instalacijom dodatne klijentske aplikacije, jer za prikaz klijentskog dela aplikacije dovoljan bilo koji veb pregledač, koji je sastavni deo bilo kog modernog operativnog sistema.

Dodatne portabilnosti radi, omogućen je pristup i preko mobilnih uređaja.

Snaga i ogroman potencijal ShareBOX aplikacije svakako jeste i njen API, putem kojeg druge aplikacije ili uređaji mogu da beleže merenja i čitaju rezultate.

Pored svega postignutog, postoji određeni prostor za unapređenje i dalji razvoj ovog softverskog rešenja.

Bilo bi poželjno dalje razvijati aplikaciju u smeru kontinualnog nadgledanja rada pneumatskih sistema, tako što bi se konstruisao jednostavan data loger uredjaj (npr. Arduino mikrokontroler sa senzorima temperature, protoka vazduha i pritiska) koji bi podatke, prikupljene pomoću priključenih senzora, kontinualno slao aplikaciji ShareBOX putem API-ja, čime bi osigurala šira praktična primena ShareBOX aplikacije u industriji.

Kontinualno nadgledanje bi zahtevalo novu funkcionalnost $\mathrm{u}$ aplikaciji, a to je sistem notifikacija $\mathrm{i}$ alarma. Korisnik bi trebalo da bude u mogućnosti da odredi predefinisane okidače koji bi alarmirali korisnika ukoliko izmerena vrednost izađe izvan predefinisanih okvira koje je korisnik ranije definisao. Time bi se omogućilo trenutno uočavanje kvara u pneumatskom sistemu.

Postupak prebacivanja podataka sa Air Box uređaja na računar nije idealan. Izvoz podataka sa Air Box uređaja i slanje podataka ShareBOX aplikaciji je jednostavan proces, ali vremenom može postati zamoran korak, koji bi mogao da se izbegne pomoću jednostavne aplikacije koja bi taj proces automatizovala. Kompanija MSR Electronics GmbH napravila je DLL koji može da se koristi za komunikaciju sa MSR Data Logerima [8], što otvara mogućnost za pisanje aplikacije za direktnu komunikaciju sa Air Box uređajem, koja, ukoliko se napiše kao veb servis, otvara mogućnost ShareBOX aplikaciji da merenja pročita direktno sa Air Box uređaja.

\section{LITERATURA}

[1] Šešlija, Dragan, and Bojan Lagod. 2006. Stanje Pneumatskih Sistema u Srbiji Sa Aspekta Energetske Efikasnosti.

[2] ISO. (2010), "Compressed air — Part 1: Contaminants and purity classes", International Standard ISO 85731, 3rd Edition, ISO copyright office, ISO International Organization for Standardization, Geneva, Switzerland.

[3] Festo. 2006. Air Box Type GHDA-FQ-M-FDMJ-A Operating Instructions. Esslingen, Germany: Festo AG\&Co. KG.

[4] CodeIgniter User Guide - CodeIgniter 3.1.9 Documentation. n.d. British Columbia Institute of Technology. Accessed 16 September 2018. https://www.codeigniter.com/user_guide/.

[5] 'APIs for Scholarly Resources | Scholarly Publishing MIT Libraries'. n.d. Accessed 20 September 2018. https://libraries.mit.edu/scholarly/publishing/apis-forscholarly-resources/.

[6] https://www.virtualbox.org/. 'Oracle VM VirtualBox'. Accessed 20 September 2018.

[7] https://www.vagrantup.com/index.html. 'Vagrant by HashiCorp'. Vagrant by HashiCorp. Accessed 20 September 2018.

[8] https://www.msr.ch/media/downloads/MSR145_DLL08-03-25.zip. 'MSR Data Loggers PC Software Free DLL’. Accessed 16 September 2018.

\section{Kratka biografija:}

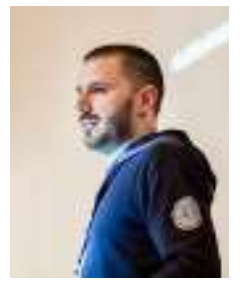

Đorđe Ungar rođen je u Vrbasu 26.10.1980. god. Gimnaziju u Vrbasu završava 1999. godine, dok studijski program „Industrijsko inženjerstvo" na Fakultet tehničkih nauka u Novom Sadu upisuje 2001. godine. Trenutno je na master akademskim studijama program ,Automatizacija procesa rada".

kontakt: djordje@ungar.rs 